\title{
REVIEW
}

\section{The Physiologic Effects of Pain on the Endocrine System}

Forest Tennant

To view enhanced content go to www.paintherapy-open.com

Received: May 20, 2013 / Published online: August 20, 2013

(c) The Author(s) 2013. This article is published with open access at Springerlink.com

\section{ABSTRACT}

Severe pain has profound physiologic effects on the endocrine system. Serum hormone abnormalities may result and these serve as biomarkers for the presence of severe pain and the need to replace hormones to achieve pain control. Initially severe pain causes a hyperarousal of the hypothalamic-pituitaryadrenal system which results in elevated serum hormone levels such as adrenocorticotropin, cortisol, and pregnenolone. If the severe pain does not abate, however, the system cannot maintain its normal hormone production and serum levels of some hormones may drop below normal range. Some hormones are so critical to pain control that a deficiency may enhance pain and retard healing.

F. Tennant $(\bowtie)$

Veract Intractable Pain Clinic, 338 S. Glendora Ave., West Covina, CA 91790-3043, USA

e-mail: veractinc@msn.com

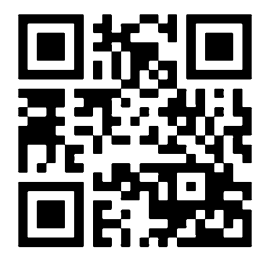

Enhanced content for this article is available on the journal web site: www.paintherapy-open.com
Keywords: Deficiencies; Endocrine system; Hormone; Hyperarousal; Pain; Replacement

\section{INTRODUCTION}

Severe pain has profound physiologic effects on the endocrine system [1-12]. Fundamentally, severe pain, whether it be acute or chronic, is a severe stressor that activates the hypothalamicpituitary-adrenal-thyroid-gonadal (HPATG) system, which is the major stress control mechanism of the body $[10,13-16]$. This system is often referred to as an 'axis' since it is a closed system with hormonal feedback or controls within the system [16-18]. This paper will refer to the 'axis' as the HPATG system. The biologic purpose of this system (see Fig. 1) is to produce additional hormones in the thyroid, adrenals and gonads, and secrete them into the serum as these compounds are required by the body for many pain-control functions, including protection and regeneration of injured tissue, immunologic activity, and metabolic controls [13, 16, 17]. Once these extra hormones, such as thyroid, cortisol, or testosterone, enter the serum, they travel throughout the body to target areas, including 


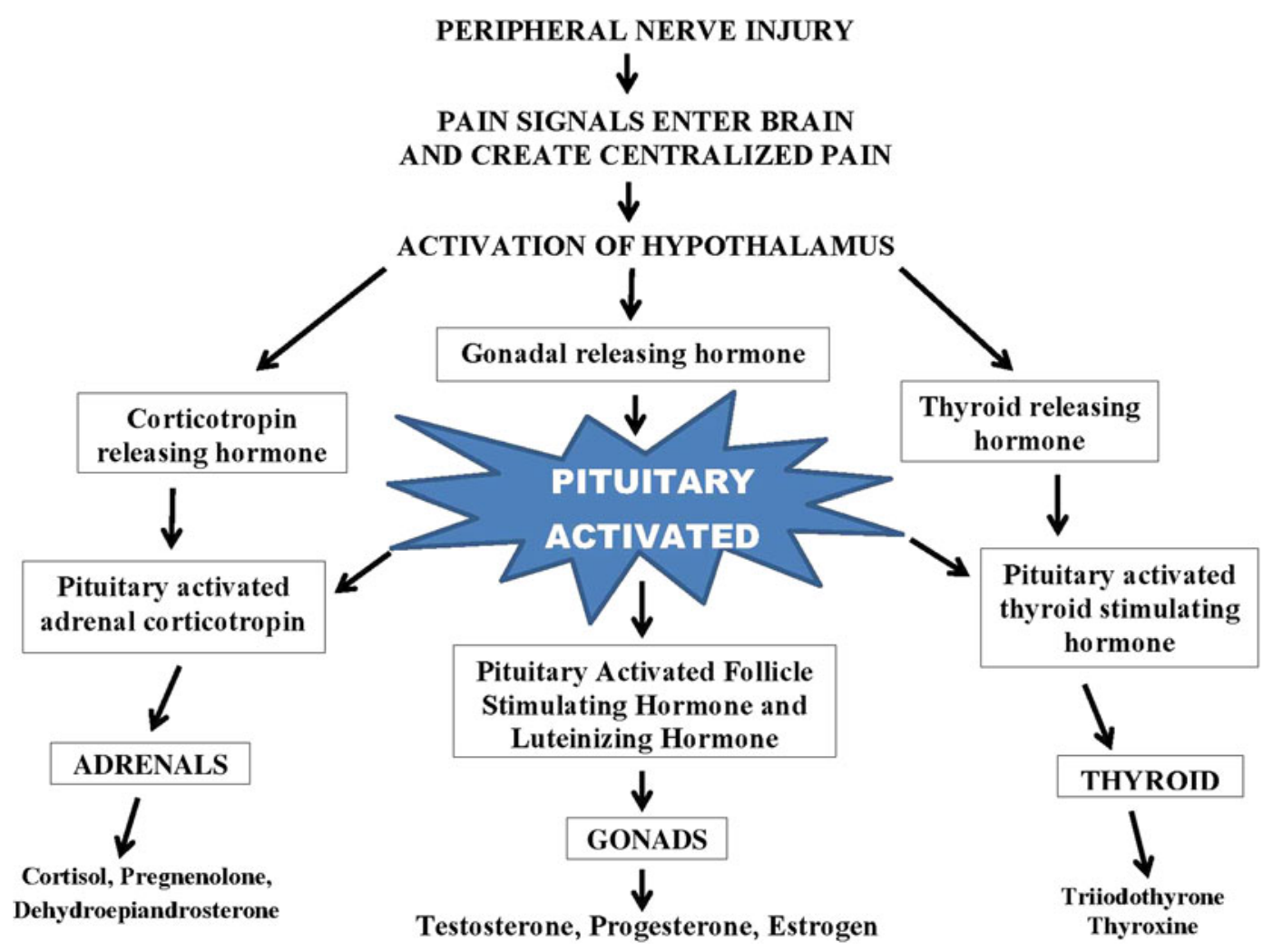

Fig. 1 Pain stimulation of the hormone system causes adrenal, gonad and thyroid hormone levels to elevate in the serum. If pain remains uncontrolled for a considerable time

injured nerves and the central nervous system (CNS) $[18,19]$. Although it is known that pain has an effect on neurohormones produced in the brain, insulin produced in the pancreas, and adrenalin produced in the adrenal medulla, there are few studies or reports on these effects [1-5], and they will not be covered here. Over the past 50 years, however, there have been numerous reports and studies on pain's physiologic effect on the HPATG system, so this is the focus of this paper [1-12, 20-30]. It is also cogent to note that the accumulated information and understanding about the effects of pain on the HPATG system is now such that testing and replacement of certain hormones should be a basic foundation of clinical pain treatment. period, hormonal depletion may occur, and serum levels drop below normal

\section{HORMONE FUNCTIONS IN PAIN CONTROL}

Adequate pain control may not be achieved without homeostasis of certain hormones [31-52]. Hormonal homeostasis is defined here as the maintenance of a hormone within a normal serum range. The critical pain-control hormones that are produced in glands outside the CNS are cortisol, pregnenolone, dehydroepiandrosterone (DHEA), progesterone, testosterone, estrogen, and thyroid (Table 1) [31-52]. Among the primary pain-control functions of these hormones are immune and anti-inflammatory actions, cellular protection, tissue regeneration, glucose control, and modulation of CNS receptors, the blood-brain 
Table 1 Hormones from peripheral glands that are critical for pain control

\begin{tabular}{l} 
Hormone \\
Cortisol \\
Dehydroepiandrosterone \\
Estrogen \\
Pregnenolone \\
Progesterone \\
Testosterone \\
Thyroid \\
\hline
\end{tabular}

Table 2 Major pain-control mechanisms of hormones

Pain-control mechanism

Anti-inflammatory action

Cellular metabolism

Cellular protection

Glucose control

Immunoreactivity

Tissue regeneration

Central nervous system functions

Receptor binding

Nerve conduction

Maintenance of blood-brain barrier

barrier, and nerve conduction (Table 2) [53-63]. Given the CNS effects of certain hormones, analgesics such as anti-depressants, neuropathic agents and opioids, may not achieve maximal analgesic responses without hormone homeostasis [19, 33, 37, 42, 49-53].

\section{The Releasing Hormones}

Pain signals that reach the brain from any injury in the peripheral nervous system activate three releasing hormones in the hypothalamus (Fig. 1) $[8,9,15,48]$. These are corticotropin releasing
Table 3 Clinical features of Cushing's Syndrome and the proportion of patients affected by these features

\begin{tabular}{ll}
\hline Clinical feature & $\begin{array}{l}\text { Proportion of } \\
\text { patients affected } \\
(\%)\end{array}$ \\
\hline Obesity or weight gain & 95 \\
Facial plethora & 90 \\
Decreased libido & 90 \\
Rounded face & 90 \\
Thin skin & 85 \\
Menstrual irregularity & 80 \\
Hypertension & 75 \\
Hirsutism & 75 \\
Depression & 70 \\
Bruise easily & 65 \\
Glucose intolerance & 60 \\
Weakness & 60 \\
Osteopenia/fracture/dental erosion & 50 \\
Nephrolithiasis & 50 \\
\hline Adapted from Newl-Price &
\end{tabular}

Adapted from Newell-Price et al. [84]

hormone (CRH), gonadal releasing hormone (GRH), and thyroid releasing hormone (TRH) [8, $9,12,48]$. These three hormones, in turn, cause the anterior pituitary to release into serum adrenal corticotropin hormone (ACTH), follicle stimulating hormone (FSH), luteinizing hormone (LH), and thyroid stimulating hormone (TSH). The end organs for stimulation are the adrenals, gonads, and thyroid, which release into the serum hormones necessary for pain control including cortisol, pregnenolone, DHEA, testosterone, progesterone, estrogen, triiodothyronine $\left(\mathrm{T}_{3}\right)$, and thyroxine $\left(\mathrm{T}_{4}\right)$ (Table 1). Adrenalin and other catecholamines are also released from the adrenal medulla, but it is only partially a result of ACTH stimulation. Serum concentrations of the pituitary and end-organ hormones can now be assayed in commercial 
laboratories and replacement hormones are also readily available. Consequently, the old saying that pain, "cannot be measured" needs to be modified. Serum levels of the pituitary and endorgan hormones noted here serve as biomarkers for uncontrolled pain (see Table 3) [3, 7, 30, 64]. In other words, it may not be possible to quantitate pain per se, but it is now possible to determine whether pain severity has reached a level that activates the HPATG system $[29,64]$. It should be noted that commercial assays for the hypothalamic-releasing hormones (CRH, GRH, $\mathrm{TRH})$ are in the developmental stages, and when available, will provide an even more direct assessment of brain overstimulation because of pain [48].

\section{The Stimulation Phase}

It is important to note that only severe pain will stimulate HPATG to the point that the end organs produce and secrete sufficient hormones to raise serum levels above normal (Fig. 1) [29, 65]. Studies show that patients with mild or intermittent pain, such as in common degenerative arthritis, have normal hormone serum levels [65]. This is an excellent practical point for the pain practitioner, since normal serum hormone levels usually mean that the patient's pain is not in need of therapy with high-risk treatment, such as long-acting opioid drugs or invasive interventions [66-74]. Put another way, hormone serum levels are excellent biomarkers that help separate severe from mild pain. If end-organ serum hormone levels are above normal, however, enhanced pain-control treatment will be needed [75]. If hormones are below normal levels, it is prudent to replace the hormones and achieve homeostasis before embarking on a therapeutic regimen that has risks, such as opioid-induced endocrine suppression [23, 66-74].

\section{The Depletion Phase}

If tissues in the hypothalamus, pituitary, adrenals, gonads, or thyroid cannot sustain the demands of severe pain, serum levels of some hormones may drop below normal levels $[10,29,64]$. Based on the clinical experience to date, the most common end-organ hormones to diminish in the serum due to uncontrolled pain are cortisol, pregnenolone, DHEA, and testosterone $[29,30,75]$. It is noted that thyroid depletion occurs, but is quite uncommon according to today's testing technology [21]. Also, some clinicians believe that thyroid depletion should be assessed according to the symptoms rather than current assays for $\mathrm{T}_{3}$ and $\mathrm{T}_{4}$ [26]. Once pain is controlled and/or hormones are replaced, serum levels will almost always return to normal. It should be emphasized that only severe pain will stimulate HPATG to the point that the end organs will not produce sufficient hormones to maintain homeostasis [65].

\section{CORTISOL ABNORMALITIES: THE MOST SERIOUS HORMONE COMPLICATIONS}

Chronic cortisol abnormalities, when levels are either too high or too low, over an extended time period are the major hormonal problems in chronic pain patients. Although the prevalence of cortisol abnormalities in chronic pain patients is unknown, excess and deficient cortisol states are starting to be recognized among pain patients $[7,10,29]$. Extended periods of exposure to excess cortisol, often referred to as Cushing's Syndrome, named after Harvey Cushing who first described the clinical signs and symptoms in patients with pituitary tumors, has serious complications [7682]. Complications include osteoporosis, 
hypertension, hyperlipidemia, and mental deficiencies (Table 3). Until now, many of these complications in pain patients were simply viewed as unrelated, random events. Table 3 lists the complications of hypercortisolemia [84]. The major complications that manifest in pain patients are osteoporosis, joint degeneration, tooth decay, hypertension, hyperlipidemia, obesity, and mental deterioration [76-82]. Although the hypercortisol complications listed here are well known, the pain patient may decondition themselves to adequately move or exercise. Consequently, multiple reasons for these complications may develop.

The disease originally described by Cushing was due to pituitary adenomas, which we now know is caused by the constant secretion of ACTH by the pituitary, which raises serum cortisol levels [76-78, 82]. In chronic pain patients, hypercortisolemia is usually episodic and only occurs during flares or periods of undertreatment that force the hypothalamus and pituitary to temporarily secrete ACTH and cortisol. Physiologically, however, it makes little difference whether high serum cortisol levels are intermittent or constant, because chronic pain patients may experience high cortisol levels, even if intermittent, over long time periods and develop sustained complications. It is very likely that joint degeneration, renal stones, vertebral collapse, hypertension, dementia, and hyperlipidemia so commonly observed in chronic pain patients are the results of intermittent hypercortisolemia over an extended period of time. Of particular concern is that hypercortisolemia causes calcium resorption, which is the apparent cause of osteoporosis, dental erosion, joint degeneration, nephrolithiasis (renal stones) and vertebral collapse. The problem of calcium resorption in pain patients may be compounded by poor diet, a lack of dietary supplements, and immobilization due to pain $[29,76,78,80,81]$. Pain practitioners must be alert and recognize these complications and evaluate patients for cortisol abnormalities.

Long-term hypocortisolemia, often known as Addison's Disease, has a different set of complications. Hypocortisolemia produces weight loss, muscle wasting, mental apathy, hypotension, and, if not detected and treated, it may cause sudden death. In patients who take opioids, testosterone is the major hormone suppressed, although opioids may also suppress cortisol. It is not known the precise opioid dosage or time frame necessary for suppression of testosterone and/or cortisol to occur. However, it is known that long-acting opioids and a longer duration of opioid treatment play a role [74]. The author has observed that suppression may occur within 90 days after a patient initiates opioid use.

Adrenal insufficiency was first described by Thomas Addison in 1855 [83]. Serum testing and even the name cortisol were not yet conceived at the time. Thomas Addison's treatise was called, "On the Constitutional and Local Effect of Disease of the Supra-Renal Capsules." He reported on 11 patients who died from severe disease of the supra-renal capsules (now called the adrenal glands), and who had a similar clinical history of weight loss, muscle wasting, lowered blood pressure, decreased mental ability, yellowish hue to the skin, and pigmentation around scars, gums, axillae, and skin creases [83]. Interestingly, two of his 11 cases had severe pain. One had facial pain and the other had extremity neuropathy. Severe, chronic pain may cause significant cortisol suppression, and a typical Addison's clinical profile will ensue (Table 4). Pain practitioners should suspect this condition if such symptoms as weight loss, muscle wasting, hypotension, and brown pigmentation on the skin are 
Table 4 Common features of hypocortisolemia in pain patients

Feature
Weakness
Weight loss
Muscle wasting
Anorexia
Hypotension
Mental apathy
Tachycardia
Yellowish hue to the skin
Pigmentation around skin creases or scars

Features were reported in Addison's original 1855 [85] description of patients who died of adrenal failure

present. Unfortunately, several conditions in pain patients may produce a physical profile similar to Addison's disease. These include immobility, inadequate diet, depression, fatigue, sleep deprivation, malabsorption, autoimmune phenomenon, and malignancy. Only serum cortisol testing can reliably distinguish adrenal insufficiency from these other unfortunate ramifications of severe, chronic pain. Hydrocortisone replacement in hypocortisolemia, as well as enhanced pain control, is essential. It can even be a simple life-saving endeavor (see Table 4) [71, 75, 84].

\section{SERUM TESTING AND REPLACEMENT}

Due to the two phases, stimulation and depletion, of pain's effect on the HPATG system, practitioners should be prepared for either too high or too low serum hormone levels when they are assayed. Table 5 shows a series of serum cortisol levels in 40 intractable pain patients referred to the Veract Intractable Pain Clinic. Note that some are high, some low, and some are normal. In particular, it should be noted that one individual had a cortisol concentration of less than $1.0 \mu \mathrm{g} / \mathrm{dL}$. This is clearly a dangerous sign, as it indicates that the patient's adrenals are nearly non-functional [81]. Death may suddenly occur in this situation. I would regard a cortisol level of less than $1.0 \mu \mathrm{g} / \mathrm{dL}$ to be a life-threatening emergency that requires immediate hormone replacement with hydrocortisone.

Replacement or partial replacement of hydrocortisone, pregnenolone, DHEA, or testosterone is rightfully emerging as a new procedure in pain treatment $[75,81]$. The benefits appear numerous. In early reports, less medication, particularly opioids, is required if hormone serum levels are normal prior to their initiation [77]. The author highly recommends that hormone testing and necessary replacement can be done before long-acting opioids and other high-risk measures are instituted.

\section{OPIOID SUPPRESSION OF HORMONES}

Opioids, particularly those that are long-acting or delivered by the intrathecal route, may suppress some hormone production [66-74]. Precise opioid dosages that may produce suppression have not been-and probably cannot be-determined due to individual biologic differences [60, 70]. It is the constancy of sustained-action opioids, however, that produces a $24-\mathrm{h}$ blood and brain concentration that does not allow the HPATG to produce its usual, normal output of hormones [63, 68, 69, 76]. Suppressed levels of 
Table 5 Mean serum cortisol concentrations in 40 consecutive patients admitted for treatment to the Veract Intractable Pain Clinic

\begin{tabular}{llllllll}
\hline Patient no. & $\begin{array}{l}\text { Serum } \\
\text { cortisol } \\
\text { concentration } \\
(\boldsymbol{\mu} \mathbf{g} / \mathbf{d L})\end{array}$ & Patient no. & $\begin{array}{l}\text { Serum } \\
\text { cortisol } \\
\text { concentration } \\
(\boldsymbol{\mu g} / \mathbf{d L})\end{array}$ & Patient no. & $\begin{array}{l}\text { Serum } \\
\text { cortisol } \\
\text { concentration } \\
(\boldsymbol{\mu g} / \mathbf{d L})\end{array}$ & Patient no. & $\begin{array}{l}\text { Serum } \\
\text { cortisol } \\
\text { concentration } \\
(\boldsymbol{\mu g} / \mathbf{d L})\end{array}$ \\
\hline 1 & 1.1 & 11 & 28.9 & 21 & 6.2 & 31 & 4.7 \\
2 & 4.9 & 12 & 11.6 & 22 & 4.0 & 32 & 16.2 \\
3 & 2.2 & 13 & 24.1 & 23 & 4.3 & 33 & 4.3 \\
4 & 2.2 & 14 & 3.9 & 24 & 30.1 & 34 & 29.8 \\
5 & 13.0 & 15 & 28.9 & 25 & 1.3 & 35 & 22.7 \\
6 & 28.5 & 16 & 32.5 & 26 & 16.1 & 36 & 25.8 \\
$7^{\mathrm{a}}$ & 0.6 & 17 & 29.0 & 27 & 18.5 & 37 & 18.7 \\
8 & 4.3 & 18 & 27.3 & 28 & 9.6 & 38 & 9.0 \\
9 & 3.7 & 19 & 19.2 & 29 & 3.4 & 39 & 21.8 \\
10 & 5.0 & 20 & 8.6 & 30 & 10.8 & 40 & 19.8 \\
\hline
\end{tabular}

Patients were referred, undertreated and claimed their pain to be disabling and constant. Note that levels were above and below the normal range, indicating uncontrolled pain. Overall mean (standard deviation, SD) cortisol level among the 40 patients: $13.9 \mu \mathrm{g} / \mathrm{dL}$ (10.3). Mean (SD) cortisol level among those $(n=12)$ with high $(>20 \mu \mathrm{g} / \mathrm{dL})$ concentration: $27.5 \mu \mathrm{g} / \mathrm{dL}(10.8)$. Mean (SD) cortisol level among those $(n=14)$ with low $(<5 \mu \mathrm{g} / \mathrm{dL})$ concentration: $3.2 \mu \mathrm{g} / \mathrm{dL}(1.4)$

${ }^{a}$ Patient had such a low level that adrenal failure and death could occur without immediate hydrocortisone replacement

testosterone are the most common problem with opioid administration, but cortisol, pregnenolone, and DHEA may also be suppressed [67, 70]. For reasons that are unclear, the thyroid hormones, $\mathrm{T}_{3}$ and $\mathrm{T}_{4}$, are seldom suppressed $[25,70]$. The predilection for testosterone suppression is believed to be due to the tendency of opioids to preferentially suppress GRH [72]. Testosterone suppression with long-acting and intrathecal opioids occurs in $75-85 \%$ of patients [66, 70, 72, 74]. Suppression may begin in the first 90 days of opioid administration and testosterone may remain suppressed as long as opioids are administered. Given this extremely high prevalence, patients who take long-acting opioids need to be regularly screened for testosterone, as well as pregnenolone, DHEA, and cortisol. Replacement of these hormones should be done, as low serum levels of any of these hormones may be associated with poor pain control, including symptoms of allodynia and hyperalgesia $[84,85]$. It is known that central sensitization and neuroinflammation due to glial cell activation are responsible for allodynia and hyperalgesia. Some hormones, particularly the glucocorticoids and sex hormones, have profound immune effects on the CNS [39, 41, 49, 54]. Hormone replacement has been reported to relieve allodynia and hyperalgesia in some patients $[75,84]$. In a patient who takes opioids, a low serum hormone concentration may be due to opioids, pain, or both. Consequently, in clinical practice, hormone replacement may have to be performed without knowing precisely which mechanism is primarily responsible for hormone deficiencies. 


\section{CONCLUSION}

The basic physiologic effect of pain on the endocrine system is one of severe stress. Pain initially stimulates the HPATG system to produce and secrete extra hormones from the adrenals, gonads, and thyroid. Hormones, including cortisol, pregnenolone, DHEA, testosterone, and thyroid $\left(\mathrm{T}_{3}\right.$ and $\left.\mathrm{T}_{4}\right)$ travel from their producing glands to distinct tissue targets, including injured nerves and the CNS. Hormones provide immunologic, antiinflammatory, and regenerative properties for cellular protection and healing. In the stimulation phase of severe pain, serum hormone levels are elevated. If pain persists unabated for too long, the hormonal system is unable to tolerate the stress of pain, and hormone production may be decreased causing serum hormone levels to drop below normal.

The most serious hormone complications of severe chronic pain are hyper- and hypocortisolemia. Cortisol serum levels rise and fall with emotion, exercise, nutrition, and disease states. Exercise is well known to positively modify cortisol levels, and this activity is highly recommended in pain patients. Chronic hypercortisolemia has numerous complications related to increased calcium resorption and includes osteopenia, joint degeneration, tooth decay, degenerative arthritis, vertebral collapse, and renal stones. Hypocortisolemia may occur in severe, undertreated pain, and cortisol levels may drop below $1.0 \mu \mathrm{g} / \mathrm{dL}$, which may be too low to sustain life. Low serum cortisol levels are clinically manifested by weight loss, muscle wasting, weakness, hypotension, and pigmentation around scars and skin creases.
Hormone serum levels serve as biomarkers for uncontrolled pain. Before embarking on therapy with long-acting opioids and other pain treatment modalities that carry risks, a minimal hormone assessment should be made to determine whether a chronic pain patient has normal serum levels of cortisol, pregnenolone, DHEA, and testosterone. Early clinical experience indicates that the use of opioids, and possibly other pharmaceutical agents, can be minimized if hormone homeostasis is achieved prior to introduction of these agents. It is cautioned, however, that the patient's report of pain and need for analgesic medication be paramount, and that hormone serum levels should never be the determinant of proper analgesia.

\section{ACKNOWLEDGMENTS}

Dr. Tennant is the guarantor for this article and takes full responsibility for the integrity of the work as a whole. No funding or sponsorship was received for this review or its publication.

Conflict of interest. Dr. Tennant declares no conflicts of interest.

Open Access. This article is distributed under the terms of the Creative Commons Attribution Noncommercial License which permits any noncommercial use, distribution, and reproduction in any medium, provided the original author(s) and the source are credited.

\section{REFERENCES}

1. Glynn CJ, Lloyd JW. Biochemical changes associated with intractable pain. $\mathrm{Br}$ Med J. 1978;1:280-1. 
2. Mellor DJ, Stafford KJ, Todd SE, et al. A comparison of catecholamine and cortisol responses of young lambs and calves to painful husbandry procedures. Aust Vet J. 2002;80:228-33.

3. Moore RA, Evans PJ, Smith RF, et al. Increased cortisol excretion in chronic pain. Anesthesia. 1983;38:788-91.

4. Nakagawa H, Hosokawa R. Study of the stress response to acute pain in the awake human. Pain Clin. 1994;7:317-24.

5. Neeck G, Crofford LJ. Neuroendocrine perturbations in fibromyalgia and chronic fatigue syndrome. Rheum Dis Clin North Am. 2000;26: 989-1002.

6. Neeck G, Federlin K, Graef V, et al. Adrenal secretion of cortisol in patients with rheumatoid arthritis. J Rheumatol. 1990;17:24-9.

7. Shenkin HA. Effect of pain on diurnal pattern of plasma corticoid levels. Neurology. 1964;14: $1112-7$

8. Straub RH, Cutolo $\mathrm{M}$. Involvement of the hypothalamic-pituitary-adrenal/gonadal axis and the peripheral nervous system in rheumatoid arthritis: viewpoint based on a systemic pathogenetic role. Arthritis Rheum. 2001;44:493-507.

9. Strittmatter M, Bianchi O, Ostertag D, et al. Altered function of the hypothalamic-pituitary-adrenal axis in patients with acute, chronic and episodic pain. Schmerz. 2005;19:109-16 (Article in German).

10. Tennant F. Intractable pain is a severe stress state associated with hypercortisolemia and reduced adrenal reserve. Drug Alcohol Depend. 2000; 60(Suppl. 1):220-1.

11. Yoshihara $T$, Shigeta $K$, Hasegawa $H$, et al. Neuroendocrine responses to psychological stress in patients with myofascial pain. J Orofac Pain. 2005;19:202-8.

12. Griep EN, Boersma JW, Lentjes EG, et al. Function of the hypothalamic-pituitary-adrenal axis in patients with fibromyalgia and low back pain. J Rheumatol. 1998;25:1374-81.

13. Akil $\mathrm{H}$, Shiomi $\mathrm{H}$, Mathews J. Induction of the intermediate pituitary by stress: synthesis and release of a non-opioid form of B-endorphin. Science. 1985;227:424-8.

14. Chikanza IC, Petrou P, Kingsley G, et al. Defective hypothalamic response to immune and inflammatory stimuli in patients with rheumatoid arthritis. Arthritis Rheum. 1992;35:1281-8.
15. Cutolo M, Foppiani L, Prete C, et al. Hypothalamicpituitary-adrenocortical axis function in premenopausal women with rheumatoid arthritis not treated with glucocorticoids. J Rheumatol. 1999;26:282-8.

16. Chrousos GP. The hypothalamic-pituitary-adrenal axis and immune-mediated inflammation. N Engl J Med. 1995;332:1351-62.

17. Bateman A, Singh A, Kral T, et al. The immunehypothalamic-pituitary adrenal axis. Endocr Rev. 1989;10:92-112.

18. McEwen BS, Biron CA, Brunson KW, et al. The role of adrenocorticoids as modulators of immune function in health and disease: neural endocrine and immune interactions. Brain Res Rev. 1997;23:79-133.

19. McEwen BS, de Kloet ER, Rostene W. Adrenal steroid receptors and action in the nervous system. Physiol Rev. 1986;66:1121-88.

20. Jorgensen $\mathrm{C}$, Bressot $\mathrm{N}$, Bologn $\mathrm{C}$, et al. Dysregulation of the hypothalamic-pituitary axis in rheumatoid arthritis. J Rheum. 1995;22: 1829-33.

21. Dons RF, Shaki KM. Changes in triidothyronine mark severe pain syndrome: a case report. Military Med. 1994;159:465-6.

22. Edmondson EA, Bonnet KA, Friedhoff AJ. The effect of hyperthyroidism on opiate receptor binding and pain sensitivity. Life Sci. 1990;47:2283-9.

23. Aloisi AM, Buonocore M, Merlo L, et al. Chronic pain therapy and hypothalamic-pituitary-adrenal axis impairment. Psychoneuroendocrinology. 2011;36:1032-9.

24. Atkinson JH Jr, Kremer EF, Ward HW, et al. Pre- and post-dexamethasone saliva cortisol determination in chronic pain patients. Biol Psychiatry. 1984;19: 1155-9.

25. Matoushek TA, Kearney TC, Lindsay TS, et al. Loss of antinociceptive effectiveness of morphine and oxycodone following titration of levothyroxine: case reports and a brief review of published literature. J Opioid Manag. 2012;8:193-6.

26. Sonkin L. Therapeutic trials with thyroid hormones in chemically euthyroid patients with myofascial pain and complaints suggesting mild thyroid insufficiency. J Back Musculoskelet Rehabil. 1997;8(2):165-71.

27. Russell U. Neurohormonal aspects of fibromyalgia syndrome. Rheum Dis Clin North Am. 1989;15: 149-68. 
28. Pillemer SR, Bradley LA, Crofford LJ, et al. The neuroscience and endocrinology of fibromyalgia. Arthritis Rheum. 1997;40:1928-39.

29. Tennant F, Hermann L. Normalization of serum cortisol concentration with opioid treatment of severe chronic pain. Pain Med. 2002;3:132-4.

30. Tennant F, Hermann L. Using biologic markers to identify legitimate chronic pain. Am Clin Lab. 2002;21(5):14-5, 18.

31. Pednekar J, Mulgaonker VK. Role of testosterone on pain threshold in rats. Indian J Physiol Pharmacol. 1995;39:423-4.

32. Fischer L, Clemente JT, Tambeli $\mathrm{CH}$. The protective role of testosterone in the development of temporomandibular joint pain. J Pain. 2007;8: 437-42.

33. Forman IJ, Tingle V, Estilow S, Caler J. The response to analgesia testing is affected by gonadal steroids in the rat. Life Sci. 1989;45:447-54.

34. Grossman A, Gaillard RC, McCartney P, et al. Opiate modulation of the pituitary-adrenal axis: effects of stress and circadian rhythm. Clin Endocrin. 1982;17:279-86.

35. Guth L, Zhang Z, Roberts E. Key role for pregnenolone in combination therapy that promotes recovery after spinal cord injury. Proc Natl Acad Sci. 1994;91:308-12.

36. Harbuz MS, Perveen-Gill Z, Lightman SL, et al. A protective role for testosterone in adjuvant-induced arthritis. Br J Rheumatol. 1995;34:1117-22.

37. Long JB, Holaday JW. Blood-brain barrier: endogenous modulation by adrenal-cortical function. Science. 1985;227:1580-3.

38. Wu FS, Gibbs TT, Farb DH. Pregnenolone sulfate: a positive allosteric modulator at the $N$-methyl-Daspartate receptor. Mol Pharmacol. 1991;40:333-6.

39. Orchinik M, Murray TF, Moore FL. A corticosteroid receptor in neuronal membranes. Science. 1991;252: 1848-51.

40. Orstavil K, Morheim I, Jorum E. Pain and small fiber neuropathy in patients with hypothyroidism. Neurology. 2006;67:786-91.

41. Ren K, Wei F, Dubner R, et al. Progesterone attenuates persistent inflammatory hyperalgesia in female rats: involvement of spinal NMDA receptor mechanisms. Brain Res. 2000;865:272-7.

42. Stafford EC, Ulibarri CM, Falk JE, et al. Gonadal hormone modulation of $\mathrm{mu}$, kappa, and, delta opioid antinociception in male and female rats. J Pain. 2006;6:261-74.

43. Holaday JW, Law PY, Loli HH, et al. Adrenal steroids indirectly modulate morphine and betaendorphin effects. J Pharmacol Exp Ther. 1979;208:176-83.

44. Joels M, DeKloet E. Control of neuronal excitability by corticosteroid hormones. Trends Neurosci. 1992;15:25-30.

45. Kibaly C, Meyer L, Patte-Mensah C, MensahNyagan AG. Biochemical and functional evidence for the control of pain mechanisms by dehydroepiandrosterone endogenously synthesized in the spinal cord. FASEB J. 2008;22:93-104.

46. Lentjes EG, Griep EN, Boersma JW, Romijn FP, de Kloet ER. Glucocorticoid receptors, fibromyalgia, and low back pain. Psychoneuroendocrinology. 1997;22:603-14.

47. Leonelli E, Bianchi R, Cavaletti $\mathrm{G}$, et al Progesterone and its derivatives are neuroprotective agents in experimental diabetic neuropathy: a multi-modal analysis. Neuroscience. 2007;144:1293-304.

48. Jain $\mathrm{R}$, Zwickler D, Hollander CS, et al. Corticotropin-releasing factor modulates the immune response to stress in the rat. Endocrinology. 1991;128:1329-36.

49. Mensah-Nyagan AG, Meyer L, Schaeffer V, Kibaly C, Patte-Mensah C. Evidence for a key role of steroids in the modulation of pain. Psychoneuroendocrinology. 2009;34(Suppl. 1): S169-77.

50. Aloisi AM, Ceccarelli I, Fiorenzani $P$, et al. Testosterone affects pain-related responses differently in male and female rats. Neurosci Lett. 2004;361:262-4.

51. Aloisi AM, Bonifazi M. Sex hormones, central nervous system and pain. Horm Behav. 2006;50:1-7.

52. Ceccon M, Runbaugh G, Vicini S. Distinct effect of pregnenolone sulfate on NMDA receptor suptypes. Neuropharmocology. 2001;40:491-500.

53. Dawson-Basoa M, Gintzler AR. Estrogen and progesterone activate spinal kappa-opiate receptor analgesic mechanisms. Pain. 1996;64:608-15.

54. Barnes PJ. Anti-inflammatory actions of glucocorticoids: molecular mechanisms. Clin Sci (Lond). 1998;94:557-72.

55. Horner HC, Packan DR, Sapolsky RM. Glucocorticoids inhibit glucose transport in 
cultured hippocampal neurons and glia. Neuroendocrinology. 1990;52:57-63.

56. Jones KJ. Gonadal steroids and neuronal regeneration: a therapeutic role. Adv Neurol. 1993;59:227-40.

57. Kimonides VG, Khatibi NH, Svendsen $\mathrm{CN}$, et al. Dehydroepiandrosterone (DHEA) and DHEAsulfate (DHEAS) protect hippocampal neurons against excitatory amino acid-induced neurotoxicity. Proc Natl Acad Sci USA. 1998;95: 1852-7.

58. Mayo W, Le Moal M, Abrous DN. Pregnenolone sulfate and aging of cognitive functions: behavioral; neurochemical, and morphological investigations. Horm Behav. 2001;40:215-7.

59. McMahon M, Gerich J, Rizza R. Effects of glucocorticoids on carbohydrate metabolism. Diabetes Metab Rev. 1988;4:17-30.

60. Munck A, Guyre PM, Holbrook NJ. Physiological functions of glucocorticoids in stress and their relation to pharmacological actions. Endocr Rev. $1984 ; 5: 25-44$.

61. Penza P, Lombardi R, Camozzi F, et al. Painful neuropathy in subclinical hypothyroidism: clinical and neuropathological recovery after hormone replacement therapy. Neurol Sci. 2009;30:149-51.

62. Schlechte JA, Sherman BM. Decreased glucocorticoids receptor binding in adrenal insufficiency. Clin Endocrinol Metab. 1982;54: 145-9.

63. Wiegers GJ, Reul JM. Induction of cytokine receptors by glucocorticoids: functional and pathological significance. Trends Pharmacol Sci. 1998;19:317-21.

64. Tennant F. How to use adrenocorticotropin as a biomarker in pain management. Pract Pain Manag. 2012;12:62-6.

65. Khorami S, Muniyappa R, Nackers L, et al. Effect of chronic osteoarthritis pain on neuroendocrine function in men. Clin Endocrinol Metab. 2006;11: 4313-8.

66. Abs R, Verhelst J, Maeysaert J, et al. Endocrine consequences of long term intrathecal administration of opioids. J Clin Endocrinol Metab. 2000;85:2215-22.

67. Daniell HW. DHEA deficiency during consumption of sustained-action prescribed opioids: evidence for opioid-induced inhibition of adrenal androgen production. J Pain. 2006;7:901-7.
68. Daniel HW. Hypogonadism in men consuming sustained-action oral opioids. J Pain. 2002;3: 377-84.

69. Daniell HW. Opioid endocrinopathy in women consuming prescribed sustained-action opioids for control of nonmalignant pain. J Pain. 2008;9:28-36.

70. Vuong C, Van Uum SH, O'Dell LE, Lutfy K, Friedman TC. The effects of opioids and opioid analogs in animal and human endocrine systems. Endocr Rev. 2010;31:98-132.

71. Elliott JA, Horton E, Fibuch EE. The endocrine effects of long-term oral opioid therapy: a case report and review of the literature. J Opioid Manag. 2011;7:145-54.

72. Finch PM, Roberts LJ, Price L, et al. Hypogonadism in patients treated with intrathecal morphine. Clin J Pain. 2000;16:251-4.

73. Roberts LJ, Finch PM, Pullan PT, et al. Sex hormone suppression by intrathecal opioids: a prospective study. Clin J Pain. 2002;18:144-8.

74. Rubinstein AL, Carpenter DM, Minkoff J. Hypogonadism in men using daily opioid therapy for non-cancer pain is associated with duration of action of opioid. Poster presentation at the 2012 Annual Meeting of the American Academy of Pain Medicine, February 23-26, 2012; Palm Springs; Abstract \#229.

75. Tennant F. Hormone therapies: newest advance in pain care. Pract Pain Manag. 2011;11:98-105.

76. Arnold G, Angeli A, Atkinson AB, et al. Diagnosis and complications of Cushing Syndrome: a consensus statement. J Clin Endocrinol Metab. 2003;88:5593-602.

77. Nieman LK, Biller BM, Findling JW, et al. The diagnosis of Cushing Syndrome: an endocrine society clinical practice guideline. J Clin Endocrinol Metab. 2008;93:1526-40.

78. Raff H, Findling JW. A physiologic approach to diagnosis of the Cushing Syndrome. Ann Intern Med. 2003;138:980-91.

79. Sapolsky RM, Krey LC, McEwen BS. Prolonged glucocorticoid exposure reduces hippocampal neuron number: implications for aging. J Neurosci. 1985;5:1222-7.

80. Krakoff L. Glucocorticoid excess syndromes causing hypertension. Cardiol Clin. 1988;6:537-45.

81. Tennant F. Complications of uncontrolled, persistent pain. Pract Pain Manag. 2004;4(1):11-14. 
82. Newell-Price J, Bertango $X$, Grossman $A B$, et al. Cushing's Syndrome. Lancet. 2006;367:1605-17.

83. Addison T. On the constitutional and local effects of disease of the supra-renal capsules. Samuel Highley, London (1855).

84. Tennant F. Hormone testing and replacement in pain patients made simple. Pract Pain Manag. 2012;12:54-62.
85. Tennant F. Corticotropin (ACTH) and cortisol serum concentrations help predict high dose opioids requirements. PAINWeek ${ }^{\circledR} 2012$ national conference on pain for frontline practitioners, Abstract 119. 